\title{
How Arab Universities Can Be Innovative
}

Arab universities, in order to be among the world's innovative universities, all the personnel thereof should be informed and educated about the following factors:

\subsection{Scientific Research Importance}

It is significant to be aware of the scientific research importance as a source of social and economic development. The term of innovative or the most innovative as a description of the university's future is the main focus of this book, so that the ambitious and talented youth feel open to new knowledge, science, economy, creativity, and arts sustainably; enabling the university to be a pioneer in our Arab and Islamic world. The time is ripe for the universities to be regarded as productive rather than consuming facilities because they present human resources, the greatest wealth of any countries. Therefore, the universities are required to provide researches and innovations that would lead to intellectual, economic, and social leadership. To achieve this target, our universities shall pioneer to embrace creative students. They have to draw students and innovative teaching staff who will come up with creative and innovative production through which the economic, social, and health affairs of community may flourish and develop. As known, the world's prestigious universities are the key catalyst and producer of innovation, business, and projects through generating new ideas. Accordingly, they contribute to supporting the economic growth business. This, of course, is not limited to the economic benefit of their research activities, but also includes, most importantly, the number of graduates as being gifted individuals contributing to the current technological and economic development.

To achieve these goals, It has become the duty of universities to train all teaching staff to recognize, learn to protect, and benefit from intellectual property when necessary, and to provide investors capable of supporting them financially. Such an academic and professional effort not only generates intellectual property but also converts it to products of commercial value that can be licensed to establish start-ups, generating new products and businesses of long-term commercial value. It is true that the complexities and risks of achieving this level of success cannot be ignored, but the reward of proper performance can also be significant. Hence, the guidance and advice shall be sought from those who have succeeded in dealing with this field, and who have direct experience in the establishment of high-tech companies of their own intellectual property.

The support, given by prestigious universities to their students and teaching staff to enter the business field on a personal level, became notably trending and is receiving a growing interest, especially in terms of education and research. Furthermore, the university, whenever having available capabilities, shall offer its facilities to enable businessmen among students and teaching staff to conduct their distinctive researches and refine their ideas. Also, the facilities and expertise should be available for outside businesses, enabling positively benefiting from ideas of research and development [112].

One of the criteria of evaluating universities on a global scale is the scientific research and the universities' innovations. Excellence in this field is a real criterion of the progress of countries and the advancement of their societies. Therefore, the scientific research conducted by universities has become a necessity to reach both of creativity and excellence for achieving the sustainable development due to how scientific research may solve many economic, health, educational, and social problems in accordance with correct scientific bases. In light of that, it was only natural for universities to pay great attention and direct their activities to train their professors and students to master the scientific research methods to acquire skills enabling them to add new knowledge to the balance of human intellect.

The acceleration of technological developments in this time poses a challenge to Arab countries, whether poor or high-income countries, as they have gained this rise in 
income only because of their natural resources rather than the possession or generation of advanced technologies. This challenge is the necessity of working hard to promote the research, development, and innovation. These countries might face what hinders the full use of their potential power in their way toward excellence in innovation. Thus, they have to overcome these obstacles to live up to the challenge represented in turning their economy into a knowledge and innovation-based economy by means of developing and stimulating both the physical and human aspects of innovation system [113-115].

To be innovative, the culture of innovation must be prevailed in the university. As known, the peoples' cultures differ from one country to another; the Chinese culture is different from the Japanese one, and cultures may differ from one institution to another or from a university to another in one country, although the culture elements are similar. These differences do not mean that one culture is better than the other.

But why are some universities innovative and creative while others are not? Why would some institutions be perceived as creative while others as not creative? We do not believe that the answer depends only on the organizational structure of university or institution, nor on the financial resources. For the culture, adapted by the institution's staff is one of the aspects that make an institution effective in the fields of innovation and creativity. The culture has become an integral part of researches in public and private institutions. It is related to the criteria, values, and principles that are created, formed, and sustained in the institution. Although organizational culture is a broad and unspecified term, the researchers agree that a certain number of ideas may be examined when one wants to understand the culture of an institution. The following points determine the framework upon which the institution's culture recognition depends [115]:

1. Mission,

2. Environment,

3. Leadership,

4. Strategy,

5. Information,

6. Socialization.

The institution's mission refers to how all staff therein identify its overarching principles, as the institution's mission provides the meaning, guidance, and goal. Moreover, the institution's mission is usually determined by its history and surrounding environment; and the concept of the environment is variable and must be considered, redefined, and interpreted constantly.
Leadership is also a cultural construction as leaders set mechanisms enabling them to work and somehow communicate in the institution, through interaction and communication methods with each other. These mechanisms also allow them to know how decisions are made, who makes them, who is aware of information, and how information is transferred; all of these factors play a major role in facilitating or hindering change. Finally, how individuals learn the institution's values and how they should behave, especially newcomers.

\subsection{Definition of the Innovative University's Culture}

Innovation is a combination of creativity, risk, and experimentation. Some universities have gained their stature when they managed to conduct successful experiments. But most analysts associated with higher education would probably say that the prevailing cultural norm is traditions, not innovation, whether the university is in Europe, Latin America, or the USA. However, the community needs good ideas to flourish. Universities need to be an incubator of such ideas. Firstly, let us get to know the innovation obstacles in universities, then have a look at the criteria that lead to innovation.

The obstacles hinder universities' creativity can be summed up as follows:

\section{Lack of motivation of change process and taking risks}

If the university or institution reaps the benefits of their usual activities and affairs, there will not be a considerable motivation for change or trying and taking risks that change could pose. An author narrates an event he has experienced personally in one of big companies over 30 years ago, where the company was a public sector company (state company) and was importing a large-scale of die from a European country. At that time, the head of research and development sector found that the template price was very high, and he wanted the company engineers to gain the practical experience necessary to manufacture such templates, especially providing the necessary equipment and skilled technicians. So, he decided to dedicate two engineers to accomplish this task and gave them the authority of ordering raw materials necessary to carry out the initial experiments. Subsequently, the production of the template was accomplished in a six-month period after several failed design, manufacturing, and heat treatments experiments. When calculating the cost of all affairs relating to the first template (wages of engineers and technicians, manufacturing 
processes, and the value of raw materials of all experiments), It was found to be less than the cost of the imported template, as well as how the two engineers had gained important experience and became experts in this matter. Unfortunately, three years later, another engineer headed the company's research and development sector. Manufacturing another part of template with volume did not exceed $1 \%$ of the previous one was discussed, but after controversy over, who would be responsible if the decision of manufacturing that part was taken and then it failed to perform its required function, and so forth, the decision was made to import and not to go through the manufacturing experience, despite there being a previous successful experience.

\section{Rules and regulations}

In addition to the existence of rules and regulations, the institutions inform their personnel about inhibitions. This kind of instructions often discourage the creative aspect of personnel, as most institutions prefer that all individuals work according to the pre-established instructions and rules. As known, the more the bureaucratic rules and regulations there are, the less the possibility of the institution's members being innovative, hence the institution will never be innovative.

3. Permanent system of monitoring individuals

Although evaluation is vital to any institution, a permanent monitoring system, especially for individuals, reduces creativity. Therefore, the evaluation system should enhance performance rather than monitor individuals for their irregularities or shortcomings, because when evaluation aims at improvement rather than punishment, creativity of individuals develops.

\subsection{Conditions of Innovation Culture}

To create and enhance an innovative environment, the university needs to develop a culture of innovation in individuals. Thus, seven conditions have been drafted to ensure that the university has a culture of innovation:

\subsubsection{Motivation and Risk Culture}

According to what is stated in reference [115], "Gerard Tellis" refers to "the deep cultural characteristics" existing in the stable organizations, which put obstacles in the way of change in fear of risks, such as the lack of reward for innovation and the severity of punishment for failure. As a result, innovators and potential innovators are afraid of failure. So, it is necessary to empower the individuals to utilize their skills optimally. Supervisors should recognize individuals and their skills and create supporting environment thereof. Hence, the concept of supporting environment will transfer, in the institution, from one individual to another so that innovation culture prevails in all active actors of institution and so the concept of rewards related to experiment deepens.

\subsubsection{Individuals Freedom of Controlling Means to Reach the Goal}

Institution should encourage the individuals to control the means to reach the agreed goal, as the personnel in an innovative institution need some kind of independence. Thus, universities need to prepare the ground for enabling the pioneers and innovators do their jobs with complete ease and support. Support is not only financial rewards but also a culture considers risks positively.

\subsubsection{Stability of Institution's Goals}

If we would like to empower individuals to think creatively, the institution's goals should not be changed day after day, when institution's officials are substituted for example. As, for example, when the president of university says: Community participation is the most significant and, four years later, a new president says: Scientific research is the ultimate objective; a confusion would be created among personnel. Or when the president of university says: Teaching is the most significant, while the vice president says: Research is the most significant. This disrupts the individual culture, resulting in their failure to manage their work optimally. Therefore, when the institution is committed to an organized activity in a specific track, the system of success will be clear for all, and individuals will know what they must do to succeed. But in case if goals keep changing, individuals become less interested in sharing creativity or taking the risk of introducing creative ideas.

\subsubsection{Prevalence of the Culture of Academic Freedom Among Individuals}

The culture of institution should adopt the principle that the individual is of a close relevance and importance to what is happening in his institution in order to enable individuals invest in their environment, care about what is going on in their institution, and be interested in its excellence. Individuals need to be aware of where the institution is headed, all with a degree of independence.

This culture: Strategic orientation and personal independence give individuals a sense of responsibility and motivate 
them to do their best to achieve the due goals. This environment is utterly different from the environment of "production lines" where individuals work as if they are copies of each other.

\subsubsection{Innovative Culture with Financial Resources and Time}

Determining a task or a goal without providing the financial support means sending contradictory messages to individuals. While resources allocation represents a strong sign referring only to what is important. So, an institution having an "innovation fund" allows good ideas to move forward, because this fund represents a strong signal of the seriousness of institution. On the other hand, if the institution punishes individuals who are seeking to get external fund to carry out their innovative business, it is probably that innovation is considered as minor or unnecessary [115].

Time is another kind of significant resources. It can stimulate innovation or do the opposite. Researches show that when individuals work constantly under the stress of deadlines, they do not look for innovative solutions, but simply choose a way enabling them to meet the deadline. Then, if innovation is significant, the institution's way of thinking regarding how the individuals spend their time should be taken into consideration, as well as helping them in allocating their time between teaching, research, innovation, and creative activities.

\subsubsection{The Institution Should Have the Culture of Collective or Joint Thinking}

The dilemma of academic environments is that professors are often isolated or introverted, each of them prefer working on their own, while the "academic community" must be a complex group. So, if we want to create an innovationoriented organization, we must pay close attention to "the culture of collective work or thinking," as the different experiences, several ways of thinking and varying ranges of age enrich the environment and make it innovative.

Collective vision comes through a variety of perspectives, which can produce an exciting thing. Diversity means the variation in viewing, classifying, understanding, and developing people toward improving the world. Therefore, the institution needs, on one hand, to pave the way for several perspectives and ideas, and, on the other hand, to be able to organize those visions into a coherent unit as players of a football team need to cooperate to achieve their goal. As far as regulation is concerned, if individuals do not gather around a certain vision, commitment to innovation decreases. Also, if we do not respect what the individual offers to the team, the institution will end up with a culture of isolation and each individual will follow his own way.

\subsubsection{The Moral Support for Institution Individuals}

Gestural and financial resources are equally important. An innovative institution needs to create a culture of experiencing and risk taking, i.e., the leadership of an institution has to provide moral support to creative people. To create a culture for innovation in a university, individuals in higher education organizations shall be trained in the art of critical thinking. In addition, it is necessary to organize group discussions to present the findings of individuals and teams, as such discussions enrich the work, create ideas, uplifting creativity, and establishing the culture of innovation. But if these groups are turned into a way to criticize others and devalue what they have done, it would result in narrowing down creativity and indicate individuals' flawed understanding of the importance of debate with scientific methodology.

\subsection{Factors That Make the University Innovative}

The scientific research and universities' innovations have become of universities evaluation criteria on a global scale. The true indicator of the progress of countries and the advancement of their communities is excellence in terms of innovation. Accordingly, scientific research is no longer a luxury for educational institutions in order to reach creativity and excellence to achieve sustainable development, it rather became a necessity for its ability to solve many economic, health, educational, and social problems, according to proper scientific bases. In light of that, it was only natural for universities to pay attention and direct their activities to train their cadre of researchers and students to master the scientific research methods that lead to creativity and subsequently innovate new products or develop existing products resulting in the advancement and prosperity of community.

To be innovative, the top management of university should create and promote number of factors and conditions that help in developing the innovation culture among its individuals, leading to be one of the worldwide innovative universities. These conditions and factor can be summed up as follows: 


\subsubsection{Spreading Innovation Culture}

Universities need to incubate good and new ideas that create innovation, helping in the prosperity of community. If innovation is a combination of creativity, risk, and experimentation, then some universities have gained their stature and even pioneering when they managed to conduct successful experiments that offered distinctive products. To be innovative, the culture of creativity should prevail in the university. So, it is necessary for the university to spread innovation culture among its personnel and work on encouraging creativity and creating innovative environment.

\subsubsection{Collaboration with Industry}

The importance of universities' role in economic and social development is obvious in that it is not limited to educational process, but it extends to the scientific research that results in innovations and inventions. These innovations and inventions are perceived as an outcome of knowledge transferring and marketing among the different industries and technologies. This results in a collaboration between the university and the various industrial sectors, and universities effectively contribute to the economic development. In addition, community gains multiple benefits through this close collaboration between the universities and industry. The importance of collaboration between universities and business organizations and establishing an active partnership between them is emphasized through the universities' contribution to developing the performance of industrial institutions and business organizations on one hand; on the other hand, promoting the universities' competitive ability as well as achieving the required quality in their programs and outputs. The need to promote links between universities and private sector has notably increased because of universities' need to develop their financial resources of the private sector, as they represent an alternate source of financing the institutions of higher education. Also, due to institutions' need to the science, innovations, and advanced services of universities. The world's universities and companies are making great efforts to develop their economic situation and increase their competitive abilities and interest in keeping up with the technological development and scientific innovations.

Here are some examples of innovative universities and their collaboration with their countries' industry:

1. In the fiscal year 2016, the expenditure on researches in MIT amounted to more than $\$ 728$ million; $19 \%$ of which came as support by industry, and there are about 700 companies that works with teaching staff and students.
2. In 2016, the University of KU Leuven, Belgium, announced a new partnership with Ford Motor company to examine the durability of 3D Printed cars' parts.

3. In the fiscal year 2014/2015, the budget of supported researches in Harvard University reached $\$ 800$ million; $\$ 50$ million of which were collected from the companies' support.

4. The expenditure on researches in University of Texas exceeds $\$ 2.7$ billion; $\$ 641$ million of which are collected from the private sector resources.

5. University of Waterloo, Canada, has been working alongside industry since its founding with industry and allowing people to own their intellectual property and benefit from the income of marketing, as the university has gathered millions of dollars for researches from donor agencies and industry. Researches were funded with $\$ 183$ million by institutions, industry, and nonprofit organizations in (2015/2016).

\subsubsection{Contributing to Creating Start-Ups and Incubators}

The results of researches come first in the innovation process, but research alone neither drives the economic growth nor achieves prosperity. Systems should be put in place to drive and support innovation so that it leads to licensing new products and/or emergence of new subsidiaries of the university. This must include teams of experts to encourage business activities and consultations and increase interaction with the industry.

Also, world's prestigious universities need systems and devoted people to interact with the business outside their walls to provide advice and expertise and support business partnerships. These are specialized fields, as individuals or work teams specialized in this field majorly benefit from external partnerships, as they are the nexus of interaction with the business world and companies. Such teams can become extraordinarily important in improving the university's characteristics and reputation in the business world on globally. Additionally, we note that specialized teams in this field are very useful in guiding the academic medium in the labyrinths of this unfamiliar world, significantly helping to manage risks and preserve the image of the university.

Start-ups must be helped to get funded from selling shares. This purpose is served by inviting large companies to establish partnership to support start-ups by providing incubation, joint funding, and guidance, as well as the possibility of giving them priority to purchase their products. Such program increases the entrepreneur's chances of surviving in the market. 
Since research and development investments yield revenues on the medium or long run rather than short run, providing financial support may be a concern for start-ups. Lately, this concern has resulted in designing programs that support or create venture capital funds. Venture capital (or risk capital) is a type of funding entrepreneurship projects in its early stages, in which it promises high potential of success and growth. However, investing in such projects is of high risk. Venture capitalists gain revenues from their shares of the project they invest in, which usually has new technology or action plan in case of high-tech companies such as: Biotechnology, information technology, software, artificial intelligence, electrical engineering, information systems, photonics, nanotechnology, nuclear physics, robots, wired and wireless communications, and automobiles. Venture capital is fundamentally different than credit or loan. In case of loans, the creditor may claim their money regardless of the company's condition or financial stability; whereas, the venture capitalist invests in a company and gets a share of it, which means that his revenues depend entirely on the project's growth and its ability of making profits. The institutions of venture capital are considered a means of financial, technical, and managerial support for start-ups of high risk and high growth and profit potentials. Examples of universities classified among aforementioned pioneering, innovative universities show how much interest these universities have for contributing to the establishment of many start-ups by their teaching staff or alumni. Here are some examples:

1. At University of Pennsylvania in 2016, 22 start-ups were established by business incubators and innovation center of the university; yielding revenue of over $\$ 50$ million.

2. In 2016, 21 new start-ups were launched at University of Washington, bringing the total number of start-ups within 10 years to 126 .

3. As for University of California, until February 2018, 1029 start-ups were established.

4. The Swiss Federal Institute of Technology in Lausanne has an innovation park which hosts laboratories, offices, and researchers from more than 150 start-ups and operating companies. In 2017 only, the school initiated 15 start-ups, and 115 companies in the Innovation Park. The start-ups have raised their budget to 112 million Swiss francs.

5. The University of Waterloo has the biggest incubator that provides over 1200 jobs and $\$ 425$ million by velocity companies.

\subsubsection{Supporting and Motivating Personnel}

Support and motivation are the main core of any successful management and they are the driving force of all institutions to move toward achieving targets. Motivation is defined as a set of factors that influence the will and motives of individuals in universities and companies to achieve these goals. There is no doubt that the provision of material and moral support to people is necessary to stimulate their creative thinking, especially the creative ones among them. Some companies such as (Walt Disney), the global company, embody the principle that (great ideas can be inspired by anyone). This is why the company offers money for any idea that can be turned into a product to encourage innovation and increase its productivity. Creating proper environment for the employee, motivating any outstanding work he does, and acknowledging his achievements as being part of the institution drives the employee's motivation over time to come from within, which, in turn, increases his trust and loyalty to his belonging to the institution, as well as developing creative thinking.

\subsubsection{Establishing a Firm for Marketing the Universities' Products}

In the University of Waterloo, Canada, there is a business management office that markets the university's products. In 2018, it was marketing for 275 patents.

\subsubsection{Raising Funds for Applied Researches}

Endeavoring to obtain funding resources for outstanding researches is an excellent way to promote scientific research and support research programs. It also encourages the necessity of keeping relevant to methodological progress that contributes to upgrading the quality of research activity. Reviewing examples of universities classified among pioneering innovative universities mentioned in this book shows how much interest these universities have in collaborating with the private or state business sectors to bring huge funds used for conducting researches; here are some examples:

1. Texas's universities spend over $\$ 2.7$ billion; $\$ 641$ million of which are obtained from private sector sources.

2. In the fiscal year 2016/2017, Stanford University announced a research budget of $\$ 1.6$ billion, as it has over 6000 projects supported from other entities.

3. As for the fiscal year 2014/2015, the budget of supported researches in Harvard University was nearly $\$ 800$ million; $\$ 50$ million of which were collected from the companies' support.

4. In July 2015, Defense Advanced Research Projects Agency (DARPA) provided \$21.6 million for the scientists of University of California, Berkeley to develop a 
"brain modem" that could directly stimulate thousands of neurons using expected light.

5. Northwestern University received $\$ 649.7$ million for funding researches within the 2015/2016 academic year.

6. The revenues of Pohang University of Science \& Technology, POSTECH, from scholarships and research contracts exceeded \$149 million in fiscal year 2015 .

7. In 2016, the revenues of California Institute of Technology reached $\$ 2.6$ billion, $46.5 \%$ of this budget is scholarships and research contracts.

\subsubsection{Reducing the Student-Faculty Members Ratio}

Below are some numbers relating to universities ranked among the world's pioneering innovative universities mentioned in this book and the student-faculty ratio. This ratio indicates the quality of interaction among them as the number of students per faculty member becomes fewer; the results of the quality of the interaction is also reflected on the quality of learning and scientific research:

1. Number of students in Duke University is 15,192 , and number of academic teaching staff members is 5022; which means that the student-faculty ratio is $3: 1$

2. In California Institute of Technology, the student-faculty ratio is $3: 1$

3. The students' number in Northwestern University is 21,823, while the academic staff members are 3313; which means that the student-faculty ratio is less than $7: 1$

\subsubsection{Research Budgets}

Here are examples of universities ranked among the pioneering innovative universities mentioned in this book. They show how great research budgets are, which helped a lot, along with other factors, to upgrade the quality of research and achieve creativity and innovation:

1. In the fiscal year 2017, the budget of scientific research in Pennsylvania State University amounted to $\$ 928$ million, while in 2016, it exceeded a billion dollars for granting the sponsored projects.

2. In the fiscal year 2015, the total research expenditure of KU Leuven-Belgium exceeded $€ 454$ million.

3. In the fiscal year 2016, the research budget in University of Washington amounted to $\$ 995$ million, equivalent to $72 \%$ of the university's annual budget.
4. University of Michigan spends annually over $\$ 1.3$ billion on researches.

5. In the fiscal year 2016/2017, Stanford University announced a research budget of $\$ 1.6$ billion.

6. Texas universities spend over $\$ 2.7$ billion on researches.

7. In the fiscal year 2016, the total research expenditure of Vanderbilt University-USA was approximately $\$ 235$ million on the scientific research, and it supported projects and researches with a total of \$214 million.

8. In 2015, University of California received over $\$ 4.97$ billion to fund its researches.

9. Northwestern University received $\$ 649.7$ million for funding researches during the 2015/2016 academic year.

10. The budget of Pohang University of Science \& Technology, POSTECH for 2016 reached \$304 million, $\$ 141$ million of which is were allocated to research, which accounted for $46 \%$ of the overall budget.

11. From 2013 to 2017 , the annual grants of research in Imperial College ranged between $£ 330$ and 436 million annually. In addition to the university's expenditures for research and equipment out of its own budget, which almost amounted to $£ 1$ billion in 2017 .

12. In 2016, the revenues of California Institute of Technology reached $\$ 2.6$ billion, $46.5 \%$ of this budget is scholarships and research contracts.

\subsubsection{Other Factors}

In addition to the previous eight main points, there are a number of factors that drive the university to be innovative. They have been deduced from the research supported by King Abdul Aziz University [116], summarized as follows:

1. Encouraging the research endeavor using crossdisciplinary method; which means forming research teams of different disciplines, as it is more creative than the other methods.

2. Forming a professional team to provide support for the identification, protection, and utilization of intellectual property by providing investors capable of supporting it financially, and to turn ideas into products of commercial value.

3. Linking the course of scientific researches to community's problems and needs and the possibility of identifying the projects of research group in consultation with the beneficiaries.

4. Linking the university education and the postgraduate researches to the national companies' requirements to enable the university to become magnet for the best talents. 
5. Developing rules and regulations to support and consolidate the cross-disciplinary research, allowing the creation of research teams from several fields for addressing complex global and community problems.

\subsection{The Kingdom Vision 2030 and Innovation}

\subsubsection{Introduction}

Allah has granted the Kingdom of Saudi Arabia many geographic, civilizational, social, demographic, and economic characteristics that enable it to occupy an esteemed position among leading countries. The vision of any country's future starts from its strengths, and this is what has been considered when shaping a vision for the Kingdom since $1452 \mathrm{H}$ (2030). The Kingdom position in the Islamic world will enable it deeply and supportively to play a leading role in the Arab and Islamic nations, and its investment power will be the key and motive to diversify the economy and achieve sustainability. Also, the Kingdom strategic location will enable it be a hub for the three continents.

The Kingdom Vision 2030 is based on three pillars shown as follows [117]:

1. Vibrant Society,

2. Thriving Economy,

3. Ambitious Nation.

These pillars are integrated and consistent with each other in order to achieve the desired goals and maximize the benefit from this vision. The first pillar (vibrant society) makes it clear that the community lies in the heart of the Kingdom's vision and is considered the basis for achieving this vision and establishing a strong foundation for the Kingdom economic prosperity. This pillar comes from the belief in the importance of building a vibrant society where its members live according to the Islamic principles and the approach of moderation, while being proud of their national identity and their ancient cultural heritage. The vision also aims to achieve a positive and attractive environment, where constituents of life quality for citizens and residents are provided. Moreover, the vision aspires for a coherent family structure and empowered social and healthcare systems.

The vision's second pillar (thriving economy) focuses on providing opportunities for everyone by building a proper education system aligned with labor market needs and developing opportunities for entrepreneurs, small-sized enterprises as well as large companies. The vision also focuses on developing investment tools to unleash the potential of promising economic sectors, diversify the economy and create new job opportunities for citizens. In addition, the vision aims to concentrating the efforts on privatizing the government services and improving the business environment. This will contribute to attract the finest international talents and the best qualitative investments and make use of the Kingdom's unique strategic location.

The vision's third pillar (ambitious nation) focuses on defining the role of an effective government that fosters efficiency, transparency, and accountability. This likely to encourage the culture of performance in order to enable the Kingdom's human resources; create the necessary environment for citizens, business sector, and non-profit sector that have them bear responsibilities; and take the initiative to face challenges and seize opportunities. In this concern, the vision states that "to be among the best 20-30 educational systems in coming years worldwide."

\subsubsection{Vision 2030, Universities and the Kingdom's Rank on Global Competitiveness Classification Index}

The Global Competitiveness Report (GCR) is an annual report that is issued by the World Economic Forum since 2004. It classifies 140 countries according to the global competitiveness standard, which is the internationally recognized ranking. In October 2018, the last report was issued where the countries' ability to provide their citizens with economic welfare and prosperity were assessed. This is in turn depends on the country's ability to benefit from its available sources. Therefore, the global competitiveness scale evaluates the economic ability of every country to achieve sustainable growth on the medium and long term. This scale depends on 12 pivots or main pillars, each of which consists of a number of indicators, with a total 98 . The report focuses on the changing nature of economic competitive ability in an increasingly changing world by new digital technologies, which introduce a new group of challenges for governments and companies.

The interest of countries and national institutions in competitiveness has increased for several reasons on top of which is to join the local and global market competition. This reflects the country's ability to achieve high growth rate and improve living standards for its citizens, as well as its appropriateness for foreign investments. The countries ranking, on competitiveness scale, can be significantly improved through higher education, continuous training, developing staff abilities and skills, in addition to making use of technology that helps to improve products quality.

In 2018, the Kingdom was ranked the 39th worldwide. Although all pillars and indicators counted for global competitiveness index are considerably based on human resources such as institutions, health care, economy, 
technological readiness, etc., universities play a key and direct role in the progress of any country when it is related to skills and innovation in particular. Among its interests, Vision 2030 focuses on improving the Kingdom's rank in competitiveness index. An article about the Kingdom's objectives by 2030 states: "Reaching one of first ten ranks in global competitiveness index," along with the focus of Vision 2030 on pillars of innovation and skills. A number of goals show the interest in innovation and education (the main responsible factors for skills). The main objectives of the Kingdom's Vision 2030 includes, for example: "Increasing the employment rates," from which the following sub objectives are derived:

1. Developing human capital according to job market needs, from which a number of detailed objectives are derived, such as:

2. Improving the basic education outputs,

3. Improving the ranking of educational institutions (such as universities),

4. Providing qualitative knowledge for distinctive individuals in fields of priority,

5. Expanding the vocational training to meet the job market needs.

Enabling the creation of job opportunities through small and medium-sized enterprises, as well as micro-projects. A number of detailed objectives are derived from this objective, such as:

1. Enabling and supporting the culture of innovation and entrepreneurship,

2. Increasing the contribution of small and medium-sized enterprises to the economy,

3. Increasing the contribution of productive families to the economy,

4. Attracting global talent that best suit the economy.

\subsubsection{Extracts from the Kingdom's Vision 2030 Showing Its Interest in Innovation and Skills}

\section{Privatizing Government Services}

We believe in the role of the private sector, and therefore, we will open up new investment opportunities in order to encourage innovation and competition, and we will remove all obstacles preventing the private sector from playing a larger role in development. We will continue to develop and activate the legislative system of markets and business. This facilitates greater opportunities for investors and enable the private sector to provide some services in the sectors of health care, education, and so forth. We will seek to shift the government's role from «a service provider» to «an organizer and monitor of sectors». We will also prepare the necessary capabilities for monitoring the level of services in the concerned authorities. As the private sector currently contributes with less than $40 \%$ of GDP, we will work on increasing this contribution by encouraging local and foreign investment in sectors of health care, municipal services, housing, finance, energy, and so forth. All of this will be subject to a flexible management and effective control.

\section{Among Our Commitments: Bigger Role for Small and Medium-Sized Enterprises}

Small and medium-sized enterprises (SMEs) are among the most important drivers of economic growth, as they work on creating job opportunities, supporting innovation, and boosting exporting. SMEs contribute with low percentage of GDP compared to advanced economies. We will seek to create suitable job opportunities for citizens all over the Kingdom by supporting entrepreneurship, privatization, and investment programs in new industries. In this respect, we established the general small and medium enterprises (SME) authority. We will continue to encourage young entrepreneurs to achieve success through establishing better regulations and by-laws, facilitating access to funding, increasing international partnerships, and allocating a greater share of governmental procurements and bids. We will support productive families that modern means of communications allowed wide marketing opportunities for them. This is through facilitating opportunities for funding micro-projects and motivating the non-profit sector to build the capabilities of those families and fund their initiatives.

SMEs contribute with only $20 \%$ of GDP, compared to the percentage achieved in advanced economies that can reach up to $70 \%$. Despite the efforts exerted to improve the level of business environment, SMEs in the Kingdom still endure slow and complex legal and administrative procedures. They also struggle to attract talents and get access to funding, as the percentage of SME funding is no more than $5 \%$ of the overall funding - a far lower percentage than the global average. We will strive to facilitate access to funding and to encourage our financial institutions to allocate up to $20 \%$ of overall funding to SMEs by 1452 AH (2030 AD).

The recently established SME authority will seek to review regulations and by-laws thoroughly, remove obstacles, facilitate access to funding, and enable the youth and innovators to market their ideas and products. At the same time, we will seek to establish more new business incubators, specialized training institutions, and venture capital funds. These will aid entrepreneurs in developing their skills and innovative skills. We will also help national SMEs in 
exporting and marketing their products and services, by supporting e-commerce and collaborating with international stakeholders.

\section{We Learn to Earn}

We will continue investing in education and training, providing our youth with the necessary knowledge and skills for their future jobs. Our objective is providing every Saudi child, wherever he/she lives, with higher quality education opportunities based on various options. We will focus particularly on developing early childhood education stages, preparing our teachers and educational leaders, and refining our educational curriculum.

We will also increase our efforts to ensure that the outcomes of our education system are in line with job market needs. As we have launched the National Labor Gateway (Taqat), and we will establish sector-specific vocational councils that will precisely determine the skills and knowledge required for each developmental sector. We will also expand vocational training in order to push forward economic development. Our scholarship opportunities will be directed to prestigious international universities and be awarded in the fields that serve our national priorities. We will also focus on innovation in advanced technologies and entrepreneurship.

\section{"We Will Focus on Innovation in Advanced Tech- nologies and Entrepreneurship"}

An important quote on supporting innovation in advanced technologies and entrepreneurship, as focusing on this field is what these developed countries seek to.

\subsection{King Abdulaziz University and the Efforts to Acquire Patents}

Innovation is the distinguished characteristic of the speed of university research development, and the following transferring the components of technology to community. There is no doubt that registered patents indicate the high position of the university and researchers. Therefore, the university spares no effort to help researchers acquire patents for their innovations and support them in all what it takes to achieve this noble aim. In the last three years (2017-2019), globally registered patents of King Abdulaziz University was successively achieved and the fruits of labor were as follows:

1. Fida Needle: A medical instrument carves body cartilages without any need for surgical intervention. It was launched in global markets in its first version under the name of "Fida Needle" at the beginning of 2017 in Global Health Exhibition in Dubai, after the journey of this invention was sponsored by King Abdulaziz
University since its launch. This invention was implemented by a team from the university consisted of the inventor Meshal Hisham Al-Harasani, Dr. Abdul Karim Reda Fida, and Dr. Faisal Hazem Zaqzouk, after the team got a globally registered patent issued by King Abdulaziz City for Science and Technology. In order to turn the idea into a physical reality, It took 6 years of work, research, studies, and participation in several conferences. The Saudi French invention also went beyond the European technologies in the same field. This is after using it in the Germen capital Berlin at Helios hospitals for the first surgery of carving children ear cartilages and modify its hillock with the minimum surgical intervention and cost. This invention is considered one of King Abdulaziz University accomplishments and its contributions in achieving the Kingdom Vision 2030 in the fields of medicine, innovation, and knowledge economy. This invention has the logos of the Kingdom's Vision 2030 and King Abdulaziz University on all global products, as it is shown in Fig. 8.1.

2. A team of experts in the anatomy department in the faculty of medicine consisting of Eng. Yahia Badr, Dr. Abdel Mounem Hayani, and Dr. Mohammad Ba-Dawoud registered a patent for a new and innovative global level method for maintaining autopsies and biopsies used in teaching students the human body formation by utilizing a method using "Shellac"rather than the harmful "Formalin".

3. Dr. Ramzi Reda Obaid, member of teaching staff of the Electrical Engineering and Computer Engineering Department at the Faculty of Engineering, registered two patents in the USA on mechanical errors in induction electrical motors. The researcher managed to develop and design two systems through a scientific research for Eaton Corporation in the States of Wisconsin and Ohio in the USA.

4. Prof. Yahia Abu Bakr Al-Hamid, Prof. Abdul Rahim bin Ahmed Al Zahrani, and Dr. Mohammad bin Abdul Rahim Daous, members of teaching staff of the Chemical Engineering and Materials Department at the Faculty of Engineering, got a patent in the field of deoxygenation operations with Luria-alumina catalyst. They got it from European Patent Office in Munich, Germany. This invention is concerned with using this dehydrogenation to turn Ethyl benzene into Alastrin as a highly important aromatic hydrocarbonic substance, widely used as a raw material for producing synthetic rubber.

5. Dr. Abdulrahman Hamed Abdullah Al-Massoud, a member of teaching staff of the Electrical Engineering and Computer Engineering Department at the Faculty of Engineering, came up with two inventions in the 
Fig. 8.1 Cover of "Fida Needle" invention

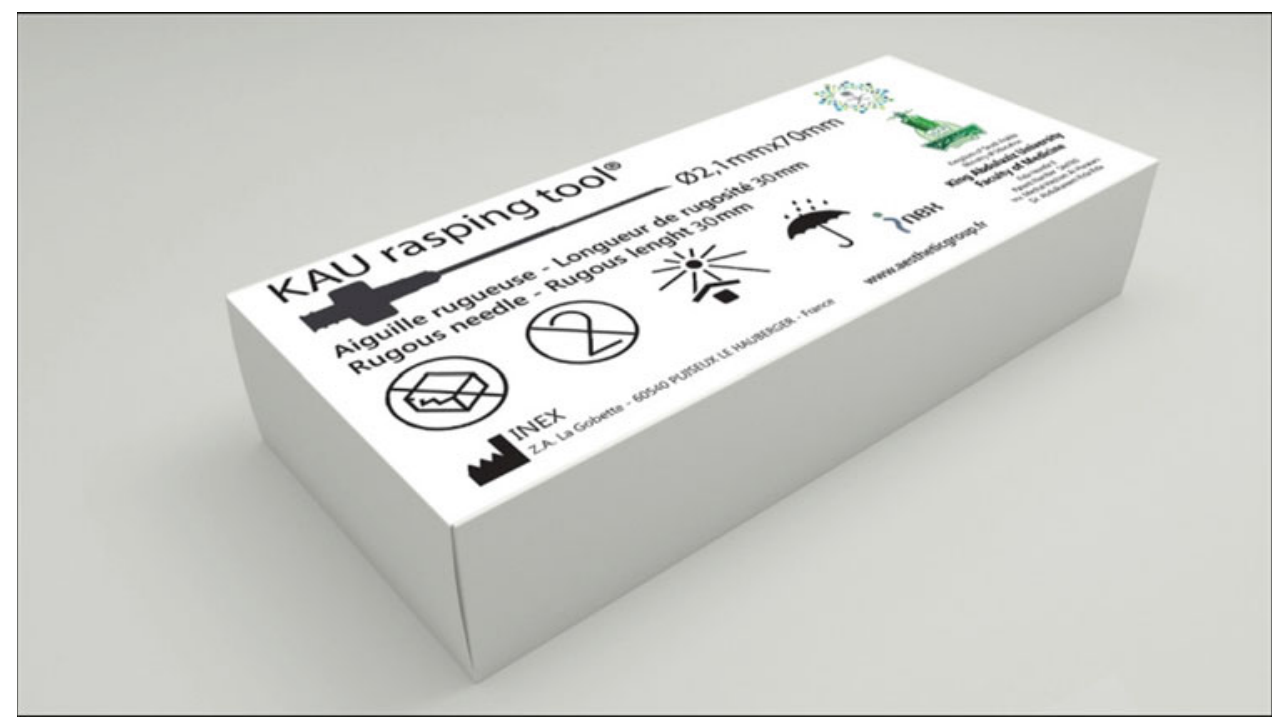

field of electrical group. He registered them in King Abdulaziz City for Science and Technology. The first invention is entitled "Neutral Point Technology for Generator Protection" and the second is entitled "Zinc and Copper Circuit Breaker."

6. A research team consisted of Prof. Fahad Al-Marzouqi and Prof. Adnan Zahed (Chemical Engineering and Materials Engineering Department at the Faculty of Engineering), Prof. Antonio Bezzi and Dr. Sayed Abdullah (Physics Department at the Faculty of Science), registered a patent in the USA for producing a new material that can be used for manufacturing car brakes from bio-colloids. The new material is a mixture of ground agricultural wastes, alcohol, natural materials, and some oxidants, all molded in the desired shapes.

7. Prof. Majed Muallah Al-Hazmi, a teaching staff member of the Mechanical Engineering Department at the Faculty of Engineering, registered a patent for flash evaporation station equipped with feeding water cooler, in the USA. The system consists of a regular flash evaporation station equipped with a cooling unit, where the water passes firstly through the cooling unit, which reduces water temperature to the last stage of evaporation stages. This leads to an increase in the evaporative range-thus increasing pure water rates. Both flash evaporation station and the cooling unit are already known regular systems. However, the point is using them in an integral way to increase the evaporation range in addition to making pure water production rates unaffected by climatic changes.

8. Prof. Majed Muallah Al-Hazmi, a teaching member staff of Mechanical Engineering Department at the
Faculty of Engineering, registered a patent for a desalination plant that operates by hydrogen fuel, in the USA. MSF or MED desalination plant uses hydrogen fuel to operate the top saltwater heater in the factory. Combusting hydrogen fuel with oxygen leads to generate carbon-free hot gases. This combustion of hydrogen fuel and oxygen occurs under liquid water spray within a directly connected room. The vapor resulted is used to heat animal feed to reach the top saltwater heater and increase its temperature up to the level needed to start evaporation. Hydrogen is produced from seawater with solar energy. In order to operate the desalination plant continuously, a suitable hydrogen storage system can be added to the hydrogen production unit. It is suggested to use the hydrogen, produced from seawater by solar energy, to generate the vapor necessary to run the thermal desalination process.

9. Prof. Majed Muallah Al-Hazmi, a teaching staff member of Mechanical Engineering Department at the Faculty of Engineering, registered a patent for a thermal inhibitor of the hollow building bricks, in the USA. The invention is a chip made of materials of relatively low thermal conductivity, folded in an inverted G-letter shape, with straight and sharp edges. After being folded, the chip is inserted into the hollows of the hollow bricks. The chip is folded with a larger height than the mid-height of the hollows in hollow bricks, in order to form a narrow path that restricts the movement of natural thermal convection currents caused by the temperature difference between the sides of the hollow building bricks. Reducing the thermal convection in the hollows of bricks increases the heat resistance of the 
walls, thus reducing the thermal leakage into the buildings, and decreasing the amount of electricity used for air conditioning. The result is reducing the energy used in houses and saving consumption costs.

10. Prof. Majed Muallah Al-Hazmi, a teaching staff member of Mechanical Engineering Department at the Faculty of Engineering, registered a patent for control drawers of thermal performance of hollow building bricks, in the USA. A building brick contains a rectangle-shaped hollow where a drawer with helicoidal path can be inserted. The helicoidal path forms a closed-end channel that can receive hot air that is directed toward the central area of the internal end of the closed path. This leads the air to accumulate in the center with no movement, thus increasing the thermal resistance of the system.
Open Access This chapter is licensed under the terms of the Creative Commons Attribution 4.0 International License (http://creative commons.org/licenses/by/4.0/), which permits use, sharing, adaptation, distribution and reproduction in any medium or format, as long as you give appropriate credit to the original author(s) and the source, provide a link to the Creative Commons license and indicate if changes were made.
The images or other third party material in this chapter are included in the chapter's Creative Commons license, unless indicated otherwise in a credit line to the material. If material is not included in the chapter's Creative Commons license and your intended use is not permitted by statutory regulation or exceeds the permitted use, you will need to obtain permission directly from the copyright holder. 